\title{
Offspring fitness and parental effects as a function of inbreeding in Epilobium angustifolium (Onagraceae)
}

\author{
BRIAN C. HUSBAND \& J ANE E. GURNEY \\ Department of Botany, University of Guelph, Guelph, Ontario, N1G 2W1 Canada.
}

\begin{abstract}
The fitness of plant offspring is determined not only by their nuclear genotype but also by non-nuclear contributions and provisioning by parents (parental effects). Nuclear and parental effects on the production and germination of offspring were estimated for self-, full-sibling and outbred pollinations in a diallel crossing design involving eight plants of Epilobium angustifolium. Seed-set and germination were significantly higher in offspring derived from outbred pollinations than from self-pollinations. Full-sib pollinations had intermediate seed-set and germination but were not statistically different from self-pollinations. The average nuclear contribution to offspring fitness was not significantly different among plants; however, variation in mean seed-set and germination percentage among particular parent combinations, which was attributable to nuclear effects, was highly significant. Parental effects accounted for a significant portion of the variation in seed-set and germination among the eight parent plants. Of these effects, 50 per cent were maternal and 50 per cent were paternal. There was no interaction between parental effects and offspring nuclear genotypes. These results suggest that, although parental effects do influence seed number and germination, parents do not differentially provision inbred and outbred offspring, and therefore differences in fitness between inbred and outbred offspring can be attributed to their nuclear genotypes.
\end{abstract}

Keywords: diallel, differential provisioning, Epilobium angustifolium, inbreeding depression, maternal effects, parental effects.

\section{Introduction}

Inbreeding depression, the reduced fitness of offspring derived from inbreeding compared with outbreeding, has now been estimated in a large number of flowering plant species and for a range of different life history stages (reviewed in Charlesworth \& Charlesworth, 1987; Husband \& Schemske, 1996). In many cases, researchers have reported significant differences in fitness between inbred (self-fertilized) and outbred offspring, at least for one stage of the life cycle. These differences are usually interpreted as the result of the offspring's nuclear genotype, of which 50 per cent is derived from each parent. However, the extent to which fitness differences are the result of non-nuclear effects and differential provisioning by parents (hereafter called parental effects) to inbred vs. outbred offspring remains unclear.

*Correspondence. E-mail: bhusband@uoguelph.ca
Parental effects represent any influence a parent has on the offspring's phenotype beyond their 50 per cent contribution to the nucleus (Roach \& Wulff, 1987; Rossiter, 1996). They may occur genetically through cytoplasmic DNA (mitochondria, chloroplasts) and endosperm, as somatic tissue in seeds and fruit (e.g. seed coat) and by parental provisioning of resources to the developing seed (Roach \& Wulff, 1987; Platenkamp \& Shaw, 1993; Mazer \& Gorchov, 1996). Depending on the specific mechanism involved, parental effects may be transmitted to different degrees by either the maternal or the paternal parent. Maternal effects, the most commonly examined form of parental effects, have been reported for many plant species (Roach, 1984; Schaal, 1984; Antonovics \& Schmitt, 1986; Schwaegerle \& Levin, 1990) and have been shown to persist for up to 2 years in some perennials (Evans \& Turkington, 1988) and for more than one generation (Alexander \& Wulff, 1985). Recent studies suggest that progeny may be subject to paternal effects as 
well (Andersson, 1990; Young \& Stanton, 1990). Whether paternal or maternal, parental effects on offspring fitness can have significant evolutionary implications. Theoretical models indicate that non-nuclear inheritance can slow and even reverse the directions of evolution compared with inheritance through nuclear, Mendelian genes (Kirkpatrick \& Lande, 1989; Lande \& Kirkpatrick, 1990; Platenkamp \& Shaw, 1993).

Parental effects may be an important cause of fitness differences between inbred and outbred offspring. In most studies of inbreeding depression, selfed and outbred offspring are generated simultaneously on the same maternal plants. This protocol creates an opportunity for parental influences to affect offspring with different nuclear genotypes differentially, particularly when resources are limiting or when offspring are sufficiently heterogeneous to create resource sinks of different strengths (Bookman, 1984; Lee \& Bazzaz, 1986). Under these circumstances, parental effects may either mask or enhance nuclear differences in embryo growth and development between inbred and outbred offspring (Wolfe, 1993; Montalvo, 1994). Differential provisioning of inbred vs. outbred offspring by parents has not been demonstrated but may partly explain previous results, such as the variation in inbreeding depression estimates depending on growing conditions (Schemske, 1983; Mitchell-Olds \& Waller, 1985; Dudash, 1990; Eckert \& Barrett, 1994), and extreme measures of inbreeding depression in the early life history stages of some species (Wolfe, 1993; Husband \& Schemske, 1995).

The perennial, herbaceous plant, Epilobium angustifolium, exhibits high levels of inbreeding depression. In a previous study, the fitness of selfed offspring was approximately 5 per cent of that in randomly outcrossed offspring (Husband \& Schemske, 1995). Much of the fitness difference was expressed as embryo abortion and low germination of selffertilized ovules. The maintenance of such high inbreeding depression is difficult to explain based on nuclear effects alone and may partly result from a maternal plant differentially provisioning its inbred and outbred offspring. Two additional observations may also be explained, in part, by maternal effects on inbreeding depression in E. angustifolium. First, there was significant variation among maternal parents in inbreeding depression; secondly, there was a correlation among maternal plants between mean number of seeds for selfed and outcrossed flowers (Husband \& Schemske, 1995). In the present study, we measured nuclear and parental effects on the fitness of inbred and outbred offspring of
E. angustifolium. We addressed the following specific questions. Does fitness vary as a function of inbreeding and is the fitness of offspring from full-sib pollinations intermediate between those from self- and outbred pollinations? Do nuclear contributions from parents have an effect on fitness? Is there a significant parental non-nuclear effect on fitness? Does the parental effect differ among inbred (full-sib) and outbred offspring?

\section{Materials and methods}

Study organism

Epilobium angustifolium L. (Onagraceae) is an erect herbaceous perennial found throughout Eurasia and North America (Mosquin, 1966). The species occurs in a variety of habitats, but is often associated with colonization of disturbed areas. Inflorescences bear up to 100 pink flowers, with 5-15 open at any one time. The flowers are insect-pollinated by various Hymenoptera and are self-compatible (Mosquin, 1966).

\section{Experimental design}

To examine nuclear and parental effects on fitness, eight plants were hand-pollinated in the University of Guelph greenhouse facilities. These parent plants were created by randomly outcrossing individuals from population D2 (Flint, 1980; Husband \& Schemske, 1995), a diploid population on the Beartooth Pass, MT, USA. The plants chosen from these original crosses for this study comprised four pairs of full-siblings (i.e. shared a common mother and father). Each pair, however, was unrelated to all other pairs (i.e. had no parents in common). The eight parent plants were crossed in all possible combinations (diallel design). Each pair of mates was crossed reciprocally; that is, each plant served as both pollen donor and pollen recipient. The eight plants were also self-pollinated. Therefore, the pollinations involved mates with three different degrees of relatedness: self, full-sib and unrelated. Each pollen donor was randomly assigned to three open flowers per plant. For each flower, pollen from at least four anthers of the pollen donor was collected and spread on the four stigma lobes of the maternal parent. All pollinations were conducted on a single inflorescence of each plant. This was done to mimic the conventional crossing design for inbreeding depression studies and to maximize the competition for resources among progeny and thereby increase the opportunities for observing parental effects. The pollinations were conducted within a growth

(C) The Genetical Society of Great Britain, Heredity, 80, 173-179. 
chamber $\left(16 \mathrm{~h}\right.$ light at $25^{\circ} \mathrm{C}$ and $8 \mathrm{~h}$ dark at $\left.20^{\circ} \mathrm{C}\right)$ in the absence of any insect pollinators.

Fruits were harvested approximately 2 weeks after pollination. To assess the effects of the pollinations, two life stages were examined: seed production, measured as the percentage of ovules forming full seeds, and percentage germination. Seeds were considered 'full' when they were plump and had a fully developed seed coat. Germination percentage was estimated by sowing 25 seeds from each cross onto moist filter paper in each of three Petri dishes and then incubating them in a growth chamber $(16 \mathrm{~h}$ light at $25^{\circ} \mathrm{C}$ and $8 \mathrm{~h}$ dark at $20^{\circ} \mathrm{C}$ ). Seeds were scored as having germinated once the radicle had emerged (Husband \& Schemske, 1995). The effects of inbreeding on seed-set and germination combined were estimated by calculating cumulative fitness, which is simply the product of the fitness of each stage.

\section{Analysis}

A one-way analysis of variance was used to test for differences in fitness between self-, full-sib and outbred pollinations. Because the variances for each pollination treatment were not uniform, a Welch's analysis of variance for unequal variances was used. For this analysis, we used the mean of the six (three for each reciprocal) replicate crosses for each parent combination. A Tukey-Kramer HSD was used to compare all possible means. An index of inbreeding depression $(\delta)$ was estimated for each stage and for cumulative fitness using $\delta=1-W_{\mathrm{s}} / W_{\mathrm{o}}$, where $W_{\mathrm{s}}$ and $W_{\mathrm{o}}$ are the mean fitnesses of selfed and outcrossed offspring, respectively.

Results from the diallel cross, excluding self-pollinations, were analysed using Cockerham \& Weir's (1977) analysis for diallel designs (model C). This model partitions seed set and germination variances into four sources: nuclear general effects, which represent differences among the eight plants in their average nuclear contribution to offspring; nuclear specific effects, which represent variation in the nuclear contribution to fitness among specific maternal-paternal plant combinations including self-, fullsib and outbred pollinations; reciprocal general effects, which indicate whether the magnitude of the difference between maternal and paternal offspring (i.e. parental effects) varies among the eight plants; and reciprocal specific effects, which represent the interaction between nuclear and parental effects. A significant reciprocal specific effect would provide support for the hypothesis that parents are differen- tially provisioning offspring from self-, full-sib and unrelated pollinations.

Estimates of parental effects were based on the differences between reciprocal crosses for each pair of plants crossed. Because reciprocal pairs will make similar nuclear contributions to offspring, any difference in performance between pairs will be a result of maternal or paternal effects. Although the proportion of the variance in parental effects attributable to maternal vs. paternal effects can be estimated in the model, independent tests of whether these values deviated significantly from zero were not available. Because data were sometimes available for only two of the original three replicate flowers pollinated and a completely balanced design was required to complete this analysis, only two pollinations were included for each cross. A Pascal program (THINK PASCAL 4.0) was written and used to analyse seed production and germination using the Cockerham and Weir model.

To clarify the nature of any significant reciprocal general effects, we conducted a one-way analysis of variance to compare all paternal and maternal means. Then, we conducted linear contrasts to examine differences between maternal and paternal means for each plant.

\section{Results}

\section{Effects of inbreeding}

Inbreeding had a significant effect on percentage seed-set and percentage germination (Table 1). Values for both life stages were significantly higher in outbred progeny than for progeny from either full-sib or self-pollinations. Crosses between unrelated plants had about 10 times higher seed-set than self-pollinated flowers, and outcrossed seed had three times more germination than self-pollinated seed. The effects of inbreeding on seed-set were not caused by reduced fertilization, as the proportion of ovules fertilized was 98 per cent and 97 per cent for self- and outbred pollinations, respectively. Although seed production and germination values for full-sib crosses were always intermediate between self and outbred crosses, they were not statistically different from selfed progeny. Similar results were found when seed production and germination were combined into a cumulative measure of fitness (Table 1). The index of inbreeding depression $(\delta)$ was 0.90 at seed-set and 0.71 at germination. Inbreeding depression based on the cumulative measure of fitness was 0.96 . 
Table 1 Mean (SE) seed production (\%) and germination (\%) of self-, full-sib and outbred offspring in Epilobium angustifolium

\begin{tabular}{|c|c|c|c|c|}
\hline \multirow[b]{2}{*}{ Fitness component } & \multicolumn{3}{|c|}{ Pollinations } & \multirow[b]{2}{*}{$F$} \\
\hline & Self & Full-sib & Unrelated & \\
\hline Seed production $(\%)$ & $6.3^{\mathrm{a}}(1.2)$ & $14.0^{\mathrm{a}}(1.9)$ & $64.8^{\mathrm{b}}(3.6)$ & $58.7^{* * *}$ \\
\hline Germination (\%) & $9.3^{\mathrm{a}}(3.4)$ & $11.1^{\mathrm{a}}(5.0)$ & $31.8^{\mathrm{b}}(1.8)$ & $21.3^{* * *}$ \\
\hline Cumulative fitness & $70.0^{\mathrm{a}}(297.4)$ & $132.9^{\mathrm{a}}(297.4)$ & $2090.8^{\mathrm{b}}(148.7)$ & $26.5^{* * *}$ \\
\hline
\end{tabular}

Mean cumulative fitness is the product of germination and seed production values for each cross, averaged across all crosses of the same type. The $F$-ratio from a one-way analysis of variance is presented. ${ }^{* * *} P<0.001$. All means sharing the same superscript are not statistically different based on a TukeyKramer HSD multiple comparison test.

\section{Nuclear vs. reciprocal effects on fitness}

Nuclear and reciprocal effects were significant sources of variation in seed-set and germination in this experiment (Table 2). For seed-set, nuclear general effects were not significant, but nuclear specific effects, which reflect variation in nuclear contributions among specific crosses, were statistically significant. This result corresponds to the large differences in mean seed-set between outbred and full-sib pollinations (Table 1). Reciprocal general effects on seed production were also significant, indicating variation in the magnitude of parental effects among the eight parents. On average, 50 per cent of the variation attributable to reciprocal effects was paternal and 50 per cent was maternal. The reciprocal general effects on seed-set resulted from one pair of full-sibs (56a and 56b), in which the

Table 2 Analysis of variance for nuclear and reciprocal effects on seed number and germination in Epilobium angustifolium

\begin{tabular}{lrcc}
\hline Source of variation & d.f. & MS & $F$ \\
\hline Seed production (\%) & & & \\
Nuclear general & 7 & 0.16 & 0.47 \\
Nuclear specific & 20 & 0.26 & $13.00^{* * *}$ \\
Reciprocal general & 7 & 0.15 & $7.50^{* * *}$ \\
Reciprocal specific & 21 & 0.02 & 0.67 \\
Error & 56 & 0.03 & \\
Germination (\%) & & & \\
Nuclear general & 7 & 0.07 & 0.44 \\
Nuclear specific & 20 & 0.05 & $2.50^{*}$ \\
Reciprocal general & 7 & 0.19 & $9.50^{* * *}$ \\
Reciprocal specific & 21 & 0.02 & 0.67 \\
Error & 56 & 0.03 & \\
\hline
\end{tabular}

***P $<0.001 ; * P<0.05$. effects depended on which plant was the paternal parent (Fig. 1). Mean seed-set for crosses involving plant 56a as the maternal parent was 61.1 per cent, but it was 33.7 per cent when it was the paternal parent. Reciprocal differences in seed-set were reversed for crosses involving plant 56b (36.4 per cent as the maternal parent and 61.4 per cent as the paternal parent). When this pair was removed from the analysis, the reciprocal general effects were no longer significant. Reciprocal specific effects were not statistically significant, indicating that non-nuclear contributions to seed-set did not differ among specific nuclear genotypes.

As with seed-set, nuclear general effects on germination were not significant, but nuclear specific effects were significant (Table 2). Also, reciprocal general effects, which reflect germination differences between reciprocal crosses, were statistically significant. Reciprocal differences were statistically significant in two of the eight plants (3b and 56a; Fig. 1), only one of which had reciprocal differences at seedset. Overall, 50 per cent of the reciprocal effects were maternal and 50 per cent were paternal. Reciprocal specific effects were not a significant source of variation in germination.

\section{Discussion}

Inbreeding depression estimates reported for Epilobium angustifolium are among the highest of any angiosperm species (Husband \& Schemske, 1995, 1996). However, the genetic basis for differences between selfed and outcrossed offspring is not well understood. The diallel crossing design used in this study confirmed that fitness, based on seed production and germination rate, was significantly affected by the degree of inbreeding, whether through selffertilization or full-sib crosses. Moreover, our study 
showed that variation in both components of fitness was the result not only of the nuclear genotype of the offspring, as is commonly assumed, but also of non-nuclear contributions from the parents. Only nuclear effects, however, differed among inbred and outbred offspring.

The reduced fitness associated with self-fertilization observed in this study was similar to results from a previous study of inbreeding depression in $E$. angustifolium (Husband \& Schemske, 1995). In the earlier investigation, seed-set in self- and cross-pollinated flowers was 8.3 per cent and 65.7 per cent respectively, compared with 6.3 per cent and 64.8 per cent in this study. Seed germination for self- and
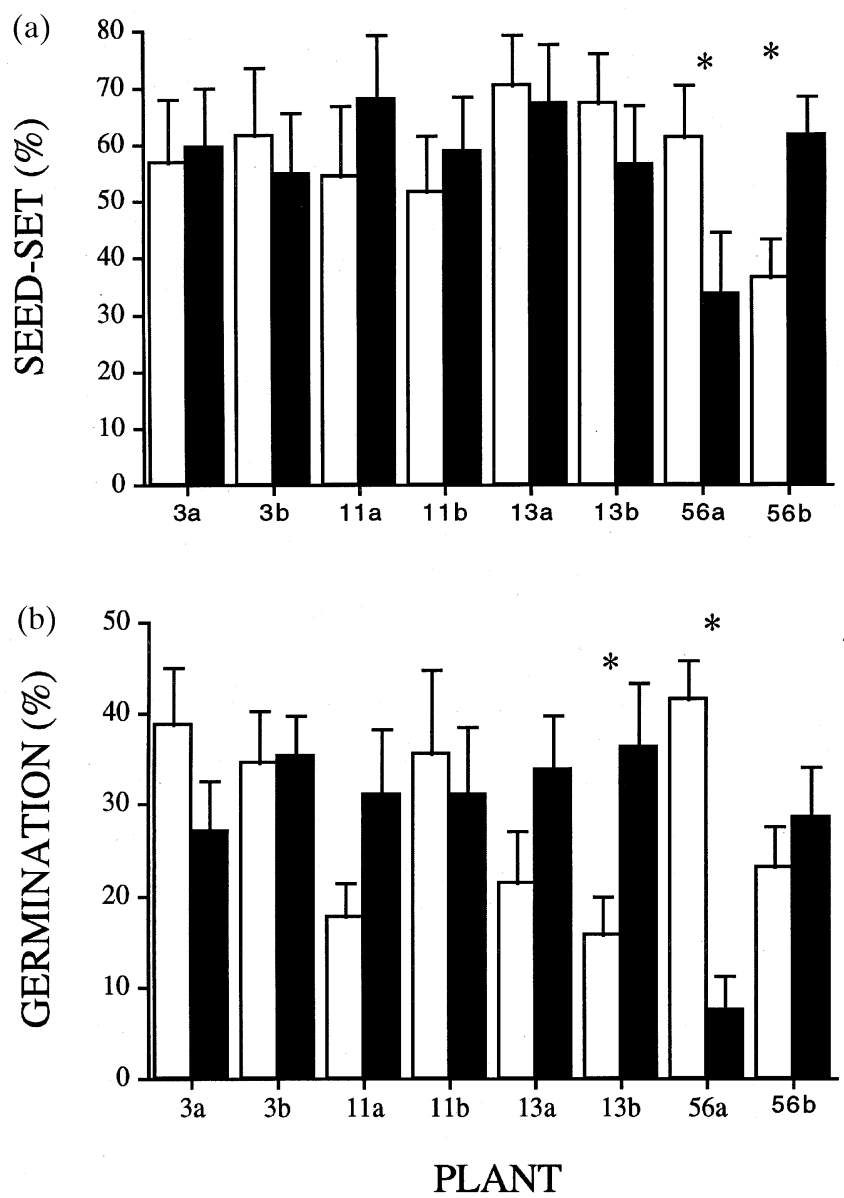

Fig. 1 Mean percentage seed production (a) and germination (b) for eight Epilobium angustifolium plants, crossed in all possible combinations. Plants with the same number represent full-siblings. Means and SEs are given for each plant as a maternal (open bars) and paternal parent (solid bars; self-pollinations not included). Asterisks indicate significant differences between maternal and paternal fitness for particular plants, based on linear contrasts. cross-pollinated offspring was higher in the previous investigation (62.1 per cent and 82.7 per cent) compared with our results (9.3 per cent and 31.8 per cent). Taking the effects of inbreeding on seed production and germination together, the magnitude of inbreeding depression in this study was 0.96, similar to the previous two-stage estimate of inbreeding depression for E. angustifolium (0.91; Husband \& Schemske, 1995). The effect of full-sib pollinations on fitness has not been examined before. The fitness of offspring from full-sib pollinations was not statistically different from self-pollinations, although the mean value was always greater. The reduced fitness of full-sib offspring and the fact that most ovules were fertilized is consistent with the interpretation that low seed-set is not the result of a prezygotic self-incompatibility response (Seavey \& Bawa, 1986), but rather is caused by the genetic load expressed in the offspring.

Based on Cockerham \& Weir's (1977) analysis of nuclear and reciprocal effects, we found no variation in general nuclear effects among the eight plants. That is, there were no differences in the nuclear contributions by each parent, when averaged across all pollinations in which they were involved. Nuclear specific effects, which reflect non-additive nuclear contributions or the effects of particular maternal $\times$ paternal combinations, were highly significant. These interactions suggest that there is a significant nuclear contribution to the differences in fitness among the self, full-sib and outbred progeny.

The significant reciprocal general effects indicate that parental effects influenced seed-set and germination in this study. For both life stages, 50 per cent of the reciprocal effects were attributable to maternal effects. Because all plants were grown in a common environment for this experiment, these non-nuclear effects are likely to result from asymmetries in genetic contributions via plastid DNA or to differences in provisioning by the parental genotype, rather than from differences in environment among parents. The specific mechanisms leading to parental effects could not be determined from the crosses conducted here. However, previous studies of $E$. angustifolium show that plastid inheritance is mostly maternal (Schmitz \& Kowallik, 1986). Parental effects through endosperm are unlikely to be important, because, in the Onagraceae, embryo sacs are four-nucleate and, therefore, maternal and paternal contributions to endosperm will be equivalent (Subramanyam \& Govindu, 1948). Interestingly, reciprocal effects in seed production and germination were not always associated with the same plants, suggesting that parental effects in later life 
stages may be in part independent of those expressed in earlier stages.

Reciprocal specific effects were not significant in this study, which indicates that there was no interaction between parental effects and the offspring's nuclear genotype. So, although parental effects contribute to seed production and germination, there was no evidence that the magnitude of parental effects differed between outbred and inbred offspring. This result suggests that parents do not differentially provision inbred and outbred offspring, despite the fact that both offspring genotypes were competing for resources on the same maternal plants. As no other diallel studies reported have involved different degrees of inbreeding, it is not known how general our results may be. Other investigations involving a similar diallel crossing design have also found evidence for nuclear and non-nuclear effects on fitness components. In a study of the determinants of propagule weight in Anthoxanthum odoratum, Antonovics \& Schmitt (1986) found significant parental effects (mostly maternal) but no evidence of differential maternal provisioning. Schwaegerle \& Levin (1990) found that, not only was there parental control of seed mass in Phlox drummondii, but that this control was differential, in that the degree of maternal control varied among specific embryo genotypes. Using a different approach, Bookman (1984) found that Asclepias fruits, whose seeds were fertilized by different fathers, differed in the likelihood of being aborted, particularly when they were competing for maternal resources. Clearly, the parental environment can differentially affect the fitness of offspring genotypes when they compete for the same maternal resources. However, more empirical evidence is necessary to ascertain the general importance of nuclear vs. non-nuclear effects on the differential fitness of offspring.

In theory, the magnitude of the fitness difference between inbred and outbred offspring (inbreeding depression) is subject to evolutionary change, as deleterious mutations are purged through inbreeding (Charlesworth \& Charlesworth, 1987). However, significant parental effects may diminish or exaggerate the fitness differences associated with inbreeding and may alter the rate and direction of evolution of inbreeding depression. Our results suggest that both nuclear and non-nuclear contributions from parents may influence offspring quality. However, there is no evidence in E. angustifolium that parents regulate the magnitude of inbreeding depression through differential provisioning. Therefore, it is likely that differences between selfed and outcrossed flowers, described as inbreeding depression, are not the product of parental effects but rather are a function of nuclear differences in offspring genotype.

\section{Acknow ledgements}

We thank A. Anderson for assistance in the greenhouse, Paul Kron for comments on the manuscript and the Natural Sciences and Engineering Research Council of Canada for financial assistance through a research grant to B.C.H.

\section{References}

ALEXANDER, H. M. AND WULFF, R. D. 1985. Experimental ecological genetics in Plantago X. The effects of maternal temperature on seed and seedling characters in $P$. lanceolata. J. Ecol., 73, 271-282.

ANDERsson, s. 1990. Paternal effects on seed size in a population of Crepis tectorum (Asteraceae). Oikos, 59, 3-8.

ANTONOVICS, J. AND SCHMitT, J. 1986. Paternal and maternal effects on propagule size in Anthoxanthum odoratum. Oecologia, 69, 277-282.

BOOKMAN, s. s. 1984. Evidence for selective fruit abortion in Asclepias. Evolution, 38, 72-86.

CHARLESWORTH, D. AND CHARLESWORTH, B. 1987. Inbreeding depression and its evolutionary consequences. Ann. Rev. Ecol. Syst., 18, 237-268.

COCKERHAM, C. C. AND WEIR, B. S. 1977. Quadratic analyses of reciprocal crosses. Biometrics, 33, 187-203.

DUDASH, M. R. 1990. Relative fitness of selfed and outcrossed progeny in a self-compatible, protandrous species, Sabatia angularis L. (Gentianaceae): a comparison of three environments. Evolution, 44, 1129-1139.

ECKERT, C. G. AND BARRETT, S. C. H. 1994. Inbreeding depression in partially self-fertilizing Decodon verticillatus (Lythraceae): population-genetic and experimental analyses. Evolution, 48, 952-964.

EVANS, R. C. AND TURKINGTON, R. 1988. Maintenance of morphological variation in a biotically patchy environment. New Phytol., 19, 369-376.

FLINT, E. P. 1980. Ecology and Distribution of Diploid and Tetraploid Epilobium angustifolium (Fireweed) in the Beartooth Mountains of Wyoming and Montana. Ph.D. Thesis, Duke University.

HUSBAND, B. C. AND SCHEMSKE, D. w. 1995. Magnitude and timing of inbreeding depression in a diploid population of Epilobium angustifolium (Onagraceae). Heredity, 75, 206-215.

HUSBAND, B. C. AND SCHEMSKE, D. w. 1996. Evolution of the magnitude and timing of inbreeding depression in plants. Evolution, 50, 54-70.

KIRKPATRICK, M. AND LANDE, R. 1989. The evolution of maternal characters. Evolution, 43, 485-503.

LANDE, R. AND KIRKPATRICK, M. 1990. Selection response in traits with maternal inheritance. Genet. Res., 55, 189-197.

(C) The Genetical Society of Great Britain, Heredity, 80, 173-179. 
LEE, T. D. AND BAZZAZ, F. A. 1986. Maternal regulation of fecundity: non-random ovule abortion in Cassia fasciculata Michx. Oecologia, 68, 459-465.

MAZER, S. J. AND GORCHOV, D. L. 1996. Parental effects on progeny phenotype in plants: distinguishing genetic and environmental causes. Evolution, 50, 44-53.

MITCHELL-OLDS, T. AND WALLER, D. M. 1985. Relative performance of selfed and outcrossed progeny in Impatiens capensis. Evolution, 39, 533-544.

mONTALVO, A. M. 1994. Inbreeding depression and maternal effects in Aquilegia caerulea, a partially selfing plant. Ecology, 75, 2395-2409.

Mosquin, т. 1966. A new taxonomy for Epilobium angustifolium L. (Onagraceae). Brittonia, 18, 167-188.

PlatenkAmP, G. A. J. AND SHAW, R. G. 1993. Environmental and genetic maternal effects on seed characters in Nemophila menziesii. Evolution, 47, 540-555.

ROACH, D. A. 1984. Ecological Genetics of Life-History Characteristics in Geranium carolinianum. Ph.D. Dissertation, Duke University.

ROACH, D. A. AND WULFF, R. 1987. Maternal effects in plants. Ann. Rev. Ecol. Syst., 18, 209-235.

ROSSITER, M. 1996. Incidence and consequences of inherited environmental effects. Ann. Rev. Ecol. Syst., 27, $451-476$.
SCHAAL, B. A. 1984. Life-history variation, natural selection, and maternal effects in plant populations. In: Dirzo, R. and Sarukhan, J. (eds) Perspectives of Plant Population Ecology, pp. 188-206. Sinauer, Sunderland, MA.

SCHEMSKE, D. w. 1983. Breeding system and habitat effects on fitness components in three neotropical Costus (Zingiberaceae). Evolution, 37, 523-539.

SCHMITZ, U. K. AND KOWALLIK, K.-V. 1986. Plastid inheritance in Epilobium. Curr. Genet., 11, 1-5.

SCHWAEGERLE, K. E. AND LEVIN, D. A. 1990. Quantitative genetics of seed size variation in Phlox. Evol. Ecol., 4, 143-148.

SEAVEY, S. R. AND BAWA, K. S. 1986. Late-acting selfincompatibility in angiosperms. Bot. Rev., 52, 195-219.

SUBRAMANYAM, K. AND GOVINDU, H. D. 1948. The development of the female gametophyte in Oenothera odorata Jacq. J. Ind. Bot. Soc., 27, 25-30.

wOLFE, L. M. 1993. Inbreeding depression in Hydrophyllum appendiculatum: role of maternal effects, crowding, and parental mating history. Evolution, 47, 374-386.

YOUNG, H. J. AND STANTON, J. L. 1990. Influence of environmental quality on pollen competitive ability in wild radish. Science, 148, 1631-1633. 